J.Lake Sci.(湖泊科学), 2016, 28(1): 68-74

DOI 10. 18307/2016. 0108

(C) 2016 by Journal of Lake Sciences

\title{
氧化还原条件对红枫湖沉积物磷释放影响的微尺度分析”
}

\author{
徐 洋 ${ }^{1}$, 陈敬安 ${ }^{2 * *}$, 王敬富 ${ }^{2}$, 罗 婧 ${ }^{1}$ \\ ( 1 : 贵州大学资源与环境工程学院,贵阳 550025) \\ (2: 中国科学院地球化学研究所环境地球化学国家重点实验室, 贵阳 550002)
}

\begin{abstract}
摘 要: 选取贵州红枫湖为研究对象, 在实验室条件下模拟了自然、好氧和厌氧条件下沉积物内源磷的释放过程, 联合应 用微电极技术和沉积物磷形态分析对沉积物一水界面开展了微尺度观测与研究. 结果表明, 厌氧条件下红枫湖沉积物总磷 含量显著降低, 且主要是 $\mathrm{NaOH}$ 提取态磷 $(\mathrm{NaOH}-\mathrm{P})$ 和残渣态磷 (rest-P) 含量降低所致, 厌氧条件下沉积物孔隙水中磷酸 盐浓度明显升高, 而好氧条件下沉积物孔隙水磷酸盐浓度显著降低, 反映厌氧条件显著促进了红枫湖沉积物磷释放. 厌氧 条件下沉积物内部溶解氧浓度下降、硫还原活动增强可能是导致 NaOH-P 释放的主要原因. $\mathrm{O}_{2}$ 浓度的降低加速了沉积物 还原作用并产生大量 $\mathrm{H}_{2} \mathrm{~S}$, 进而与二价铁离子形成硫化亚铁沉淀, 最终导致 $\mathrm{NaOH}-\mathrm{P}(\mathrm{Fe}-\mathrm{P})$ 释放到孔隙水中. 好氧条件向 厌氧条件的转换可通过改变沉积物内部 $\mathrm{pH}$ 值分布和微生物活动促使 rest-P 释放: 厌氧条件下, 厌氧微生物不仅可以消耗 硫酸根产生 $\mathrm{H}_{2} \mathrm{~S}$, 导致 $\mathrm{pH}$ 值降低, 还可消耗有机质, 将有机磷转变为无机磷.上述研究结果表明, 沉积物一水界面氧化还原 环境可影响沉积物氧渗透深度、 $\mathrm{pH}$ 值分布、微生物活动、硫循环以及有机质降解过程, 进而控制沉积物磷的形态转化与释 放.联合应用微电极技术和沉积物磷形态分析对湖泊沉积物一水界面开展微尺度观测研究是揭示沉积物内源磷释放机制 与控制因素的有效途径.
\end{abstract}

关键词: 氧化还原环境; 微电极; 微尺度;沉积物内源磷; 红枫湖

\section{The micro-scale investigation on the effect of redox condition on the release of the sedi- ment phosphorus in Lake Hongfeng}

\author{
XU Yang ${ }^{1}$, CHEN Jing' ${ }^{2}{ }^{2 * *}$, WANG Jingfu ${ }^{2} \&$ LUO Jing ${ }^{1}$ \\ (1: College of Resources and Environmental Engineering, Guizhou University, Guiyang 550025, P.R. China) \\ (2: State Key Laboratory of Environmental Geochemistry, Institute of Geochemistry, Chinese Academy of Sciences, Guiyang \\ 550002, P.R.China)
}

\begin{abstract}
In this paper, Lake Hongfeng, located in Guizhou Province, was chosen to study the release process of the sediment phosphorus under the natural, aerobic and anaerobic conditions. Microscale observation of the physical and chemical properties of sediment-water interface by microelectrode technology was used, together with traditional P-speciation analysis, to explore the P-releasing mechanisms. The results showed that under anaerobic conditions, the total content of phosphorus in the sediment in Lake Hongfeng decreased significantly, which was mainly caused by the reduction of $\mathrm{NaOH}-\mathrm{P}$ and rest-P, indicating that the aerobic condition promoted the phosphorus release from sediments. The concentration of phosphate in the pore water of sediment increased greatly under anaerobic condition, and the trend was contrary to that under aerobic condition. Under the anaerobic condition, concentration of dissolved oxygen decreased and sulfate reduction was enhanced, which released NaOH-P from the sediment. Decrease of $\mathrm{O}_{2}$ accelerated the sediment reducing processes and produced a large amount of $\mathrm{H}_{2} \mathrm{~S}$, which combined with ferrous icon to form the precipitation-ferrous sulfide, resulting in release of $\mathrm{NaOH}-\mathrm{P}(\mathrm{Fe}-\mathrm{P})$ into the pore water. The conversion of aerobic to anaerobic condition could promote the release of rest-P by changing the distribution of $\mathrm{pH}$ value in the sediment as well as microbial activities. Under the anaerobic condition, anaerobic microorganisms could not only contribute to the sulfate reduction and $\mathrm{H}_{2} \mathrm{~S}$ production, leading to $\mathrm{pH}$ decrease, but also consume organic matter and convert organic phosphorus into inorganic phosphorus. The redox envi-
\end{abstract}

* 国家自然科学基金项目 $(41173125,41403113)$ 资助. 2015-01-27 收稿; 2015-03-27 收修改稿.徐洋( 1988 ), 男, 硕士研 究生;E-mail: 1061279190@qq.com.

** 通信作者; E-mail : chenjingan@vip.skleg.cn. 
ronment of sediment-water interface could affect the penetration depth of sediment-oxygen, $\mathrm{pH}$ distribution, microbial activity, sulfur cycle as well as organic matter degradation process, which controlled the speciation transformation and release of sediment phosphorus. Microelectrode technology, together with traditional P-speciation analysis, is an effective way to reveal the release mechanisms of sediment phosphorus as well as the control factors.

Keywords: Redox environment; microelectrode; microscale; sediment phosphorus; Lake Hongfeng

湖泊富营养化是我国当前面临的最严峻的水环境问题之一 ${ }^{[1]}$. 磷被认为是造成湖泊富营养化最重要的 限制性因子 ${ }^{[2]}$. 湖泊水体磷来源可分为两类:一是外源输人, 如工业废水、城镇生活污水、农业面源污染等; 二 是内源输人, 即湖泊沉积物内源磷释放. 随着外源污染物输人逐步得到有效控制, 沉积物内源磷释放已成为 控制水体富营养化的重要因素.

影响湖泊沉积物磷释放的环境因素众多, 其中关键因素主要有温度、 $\mathrm{pH}$ 值、溶解氧、氧化还原电位、生 物作用以及扰动等. 金相灿等 ${ }^{[3]}$ 对玄武湖沉积物中磷释放的研究表明, $\mathrm{pH}$ 值为中性时底泥释磷最少, 当偏离 中性时, 释磷即增加. 候立军等 ${ }^{[4]}$ 在对苏州河底泥内源磷释放的研究中发现当底泥存在微生物作用时, 其内 源磷的释放量明显高于没有微生物作用时.温度、扰动、氧化还原电位以及溶解氧的变化均会导致沉积物内 源磷释放量的改变 ${ }^{[5]}$. 大量研究表明, 溶解氧是沉积物磷释放的关键控制因素, 沉积物磷在戻氧条件下易于 释放, 而好氧条件可抑制沉积物磷的释放. 溶解氧对于沉积物内源磷释放的控制主要是通过影响沉积物中的 铁锰氧化物、硫的氧化还原以及微生物的新陈代谢来实现 ${ }^{[6]}$. 好氧条件下, 铁锰以氧化物或氢氧化物形式存 在, 具有较强的磷酸盐吸附能力, 可有效阻止沉积物磷向上覆水体释放. 戻氧条件下, 铁镇氧化物被还原, 磷 酸盐解吸释放 ${ }^{[7-12]}$. 深人揭示好氧与厌氧条件下沉积物化学组成和微观结构的差异对阐明沉积物内源磷释 放机制和有效控制内源磷释放具有重要意义.

目前, 对好氧与厌氧条件下沉积物化学组成的研究往往是将沉积物进行分层取样后再测 ${ }^{\text {量 }}{ }^{[13]}$. 这类方 法破坏了沉积物内部结构, 往往难以反映沉积物真实状况. 近年来快速发展的微电极技术可在不破坏沉积物 内部结构的前提下获取沉积物化学组成和微观结构信息 ${ }^{[14-16]}$, 为对比研究好氧与厌氧条件下沉积物的化学 组成和微观结构提供了有力手段.

红枫湖是贵州高原中部的一座典型人工深水型水库, 但近年来水体富营养化趋势明显, 直接威胁着区 域供水和生态安全. 以往研究已揭示红枫湖底泥具有极高的氮、磷营养盐负荷和内源磷释放风险 ${ }^{[17]}$, 但对不 同氧化还原条件下沉积物的化学组成和微观结构尚缺乏系统对比研究. 为此, 本文选取贵州红枫湖为研究对 象, 采用微电极技术深人开展自然、好氧和戻氧条件下沉积物的化学组成和微观结构变化的微尺度研究, 以 揭示沉积物内源磷释放机制, 为湖泊底泥内源污染控制提供科学指导.

\section{1 材料与方法}

\section{1 研究区概况}

红枫湖 $\left(26^{\circ} 31^{\prime} \sim 26^{\circ} 34^{\prime} \mathrm{N}, 106^{\circ} 24^{\prime} \sim 106^{\circ} 43^{\prime} \mathrm{E}\right)$ 位于清镇市、平坝县和安顺市西秀区境内, 是贵州省 1958 年开始在猫跳河干流上筑坝兴建的一座高原人工河道水库, 于 1960 年 5 月建成蓄水. 红枫湖流域面积 $1596 \mathrm{~km}^{2}$, 正常水位海拔 $1240 \mathrm{~m}$ 时湖泊水面面积 $57.2 \mathrm{~km}^{2}$. 湖泊长 $16 \mathrm{~km}$, 平均宽 $4 \mathrm{~km}$, 最大水深 $45 \mathrm{~m}$, 平均 水深 $10.5 \mathrm{~m}$, 总库容 $6.01 \times 10^{8} \mathrm{~m}^{3}$. 红枫湖是目前贵州省中部最大的人工水库, 兼具发电、防洪、旅游、工农业 用水、饮用水源、水上运动、调节生态环境等多种功能, 其主要人湖河流包括羊昌河、猫跳河、麻线河以及桃 花源河等 ${ }^{[18]}$. 选取大坝前深水区 (水深 $25 \sim 30 \mathrm{~m}$ ) 作为代表性研究点位 (图 1).

\section{2 样品采集与前处理}

利用无扰动沉积物采样器 ${ }^{[19]}$ 采集沉积物柱芯, 现场利用锡簿纸包裹避光并迅速带回实验室. 在实验室 将沉积物柱芯分别装人自制的有机玻璃容器内, 沿容器壁缓慢加人 $0.45 \mu \mathrm{m}$ 滤膜过滤后的湖水静置培养 2 周, 沉积物与上覆水的体积比为 $1: 7$.

\section{3 实验方法}

将平衡好的沉积物柱芯放人温度为 $18^{\circ} \mathrm{C}$ 的恒温培养箱 (SPX-70B III, TAISITE), 在 3 种不同环境状态下 


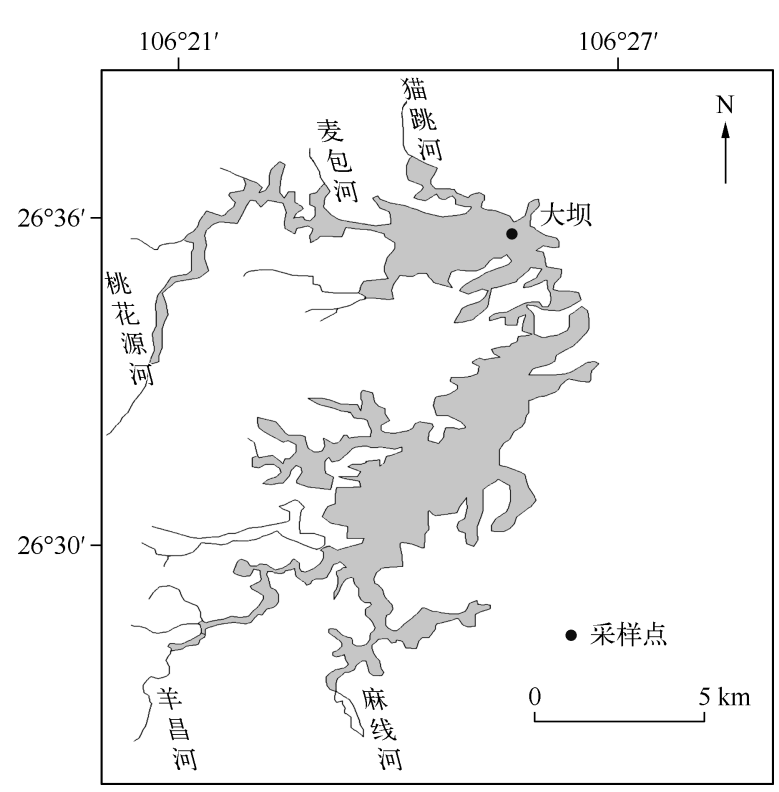

图 1 红枫湖采样点位置

Fig.1 Location of sampling site in Lake Hongfeng
(自然状态、充 $\mathrm{O}_{2}$ 和充 $\mathrm{N}_{2}$ ) 进行恒温、避光培 养, 实验周期为 $36 \mathrm{~d}$, 具体处理如下: (1) 对照 组: 在自然条件下培养, 不进行任何处理; (2) 充 $\mathrm{O}_{2}$ 组:使用空气泉连续曝气, 维持 DO 浓 度 $\geqq 9.0 \mathrm{mg} / \mathrm{L}$; (3) 充 $\mathrm{N}_{2}$ 组: 通人纯度为 $99 \%$ 的 $\mathrm{N}_{2}, \mathrm{~N}_{2}$ 通人时间每次为 $1 \mathrm{~h}$, 充气后使用凡士林 进行密封处理, 维持 DO 浓度 $<1 \mathrm{mg} / \mathrm{L}$.

实验结束后, 利用微电极测量系统 (丹麦 Unisense 公司) 对不同培养条件下的沉积物一水 界面溶解氧、 $\mathrm{H}_{2} \mathrm{~S}$ 以及 $\mathrm{pH}$ 值进行微尺度剖面测 定. $\mathrm{O}_{2}$ 的穿刺步进设为 $100 \mu \mathrm{m}$, 测量及响应时 间设为 $16 \mathrm{~s} ; \mathrm{H}_{2} \mathrm{~S}$ 以及 $\mathrm{pH}$ 值穿刺步进设为 300 $\mu \mathrm{m}$, 测量及响应时间设为 $20 \mathrm{~s}$. 测量结束后, 将 沉积物柱芯按照 $0 \sim 1 、 1 \sim 2 、 2 \sim 3 \mathrm{~cm} 、 \cdots \cdots$ 进行 分层取样, 离心获得孔隙水, 测定孔隙水中的 溶解态活性磷 (SRP) 浓度以及沉积物中磷的 赋存形态. 孔隙水 SRP 浓度采用钼锑抗分光光 度法( GB 11893-1989) 测定, 沉积物磷赋存 形态采用 Hupffer 等发展建立的化学连续提取 法进行测定 $(\text { 表 1 })^{[20]}$.

表 1 沉积物磷赋存形态的化学连续提取方法 ${ }^{[20]}$

Tab.1 The chemical continuous extraction method of sediment phosphorus forms

\begin{tabular}{|c|c|}
\hline 提取剂 & 所提取的磷形态 \\
\hline a. $\mathrm{NH}_{4} \mathrm{Cl} 1 \mathrm{~mol} / \mathrm{L}$ & 孔隙水中松散吸附在物质表面的 (如铁和 $\mathrm{CaCO}_{3}$ 表面) 立即可用的磷, 即弱吸附态磷. \\
\hline b. $\mathrm{BD} 0.11 \mathrm{~mol} / \mathrm{L}$ & 氧化还原敏感的磷, 主要指被铁的氢氧化物和锰的化合物约束的磷. \\
\hline c. $\mathrm{NaOH} 1 \mathrm{~mol} / \mathrm{L}$ & $\begin{array}{l}\text { 溶解性活性磷 (SRP) : 可与 } \mathrm{OH}^{-} \text {离子进行交换的铁铝金属氧化物约束的磷; 无机磷化合物: 主要 } \\
\text { 为铁铝结合态磷; 微生物磷 (NRP) : 非活性磷、总磷与 SRP 的差值, 包括碎屑中有机磷和聚磷以 } \\
\text { 及腐殖酸化合物结合的磷. }\end{array}$ \\
\hline d. $\mathrm{HCl} 0.5 \mathrm{~mol} / \mathrm{L}$ & 碳酸盐结合的磷和磷灰石磷, 微量的水解有机磷, 主要为钲结合态磷. \\
\hline $\begin{array}{l}\text { e. } 500^{\circ} \mathrm{C} \text { 灰化 } 2 \mathrm{~h} \\
\mathrm{HCl} 3.5 \mathrm{~mol} / \mathrm{L}\end{array}$ & 有机磷和其他耐火物质中的磷. \\
\hline
\end{tabular}

\section{4 沉积物一水界面 $\mathrm{O}_{2}$ 扩散通量计算}

利用 Fick 第一定律对不同氧化还原状态下的氧气扩散通量进行计算 ${ }^{[21]}$ :

$$
J=-D\left(\frac{d c}{d x}\right)
$$

式中, $J$ 为物质的扩散通量 $\left(\mathrm{nmol} /\left(\mathrm{m}^{2} \cdot \mathrm{s}\right)\right) ; D$ 为扩散系数 $\left(\mathrm{m}^{2} / \mathrm{s}\right)$; 括号内部表示物质的浓度梯度;负号表 示浓度梯度方向与扩散通量方向相反. 其中 Fick 定律的扩散系数 $D$ 代表单位浓度梯度下的扩散通量, 它表 示某个组分在介质中扩散的快慢, 是物质的一种传递性质.液体中的扩散系数其量级为 $10^{-9} \mathrm{~m}^{2} / \mathrm{s}$, 水中的扩 散系数常用 wilke-chang 公式估算 ${ }^{[22]}$ :

$$
D_{\mathrm{AB}}=7.4 \times 10^{-15} \frac{\left(\varphi M_{\mathrm{B}}\right)^{1 / 2} T}{\mu V_{\mathrm{A}}^{0.6}}
$$

式中, $D_{\mathrm{AB}}$ 是溶质 $\mathrm{A}$ 在溶剂 $\mathrm{B}$ 中的扩散系数 $\left(\mathrm{m}^{2} / \mathrm{s}\right) ; T$ 为溶液的温度 $(\mathrm{K}) ; \mu$ 为溶剂 $\mathrm{B}$ 的粘度 $(\mathrm{Pa} \cdot \mathrm{s}) ; M_{\mathrm{B}}$ 为 
溶剂 $\mathrm{B}$ 的摩尔质量 $(\mathrm{g} / \mathrm{mol}) ; \varphi$ 为溶剂的缔合参数, 水为 $2.6 ; V_{\mathrm{A}}$ 为溶质 $\mathrm{A}$ 在正常沸点下的分子体积 $\left(\mathrm{cm}^{3} / \mathrm{mol}\right)$, 由正常沸点下的液体密度来计算.

\section{2 研究结果}

\section{1 不同培养条件下沉积物孔隙水磷酸盐浓度变化}

不同培养条件下, 孔隙水中的 SRP 浓度表现为充 $\mathrm{N}_{2}$ 组>对照组>充 $\mathrm{O}_{2}$ 组 (图 2). 充 $\mathrm{N}_{2}$ 组孔隙水 SRP 浓 度约为 $0.309 \mathrm{mg} / \mathrm{L}$, 是对照组的 2 倍左右, 而充 $\mathrm{O}_{2}$ 组的孔隙水 $\mathrm{SRP}$ 浓度仅为 $0.023 \mathrm{mg} / \mathrm{L}$. 显然, 厌氧使得沉积 物孔隙水中磷酸盐浓度明显升高, 而好氧条件下沉积物孔隙水磷酸盐浓度显著降低.

\section{2 不同培养条件下沉积物磷赋存形态变化}

不同培养条件下, 沉积物磷赋存形态变化如图 3 所示. 充 $\mathrm{N}_{2}$ 组和充 $\mathrm{O}_{2}$ 组的沉积物总磷 ( Sum-P) 含量与 对照组相比均有不同程度的降低, 且充 $\mathrm{N}_{2}$ 组降低显著 (降低了 $378.9 \mathrm{mg} / \mathrm{kg}$ ). 这种变化主要是由 $\mathrm{NaOH}$ 提取 态磷 ( NaOH-P) 和残渣态磷 ( rest-P) 含量降低引起的. NaOH-P 是红枫湖沉积物磷最主要的赋存形态, 其含量 约占总磷含量的 $57.8 \%$, 其次是 rest-P, 约占 $22.1 \%$, 其余 $20.1 \%$ 为 $\mathrm{NH}_{4} \mathrm{Cl}$ 提取态磷 $\left(\mathrm{NH}_{4} \mathrm{Cl}-\mathrm{P}\right) 、 \mathrm{BD}$ 提取态磷 (BD-P) 和 HCl 提取态磷 ( HCl-P). 充 $\mathrm{N}_{2}$ 条件下, NaOH-P 含量明显减少, 而孔隙水中 SRP 浓度有较大的升高 (图 2), 说明 NaOH-P 释放进人孔隙水和上覆水. 充 $\mathrm{O}_{2}$ 条件下, 沉积物总磷含量略有降低, NaOH-P 含量略微降 低是导致此现象的主要原因. 与充 $\mathrm{N}_{2}$ 条件不同的是, 充 $\mathrm{O}_{2}$ 条件下, 沉积物孔隙水中 $\mathrm{SRP}$ 浓度 $(0.023 \mathrm{mg} / \mathrm{L})$ 明 显低于对照组 $(0.151 \mathrm{mg} / \mathrm{L})$.

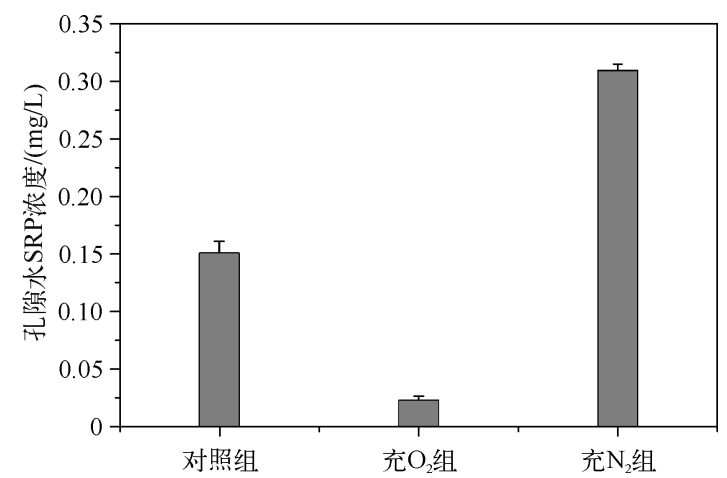

图 2 不同培养条件下沉积物孔隙水中 SRP 浓度

Fig. 2 The sediment pore water SRP concentration under different cultivate conditions

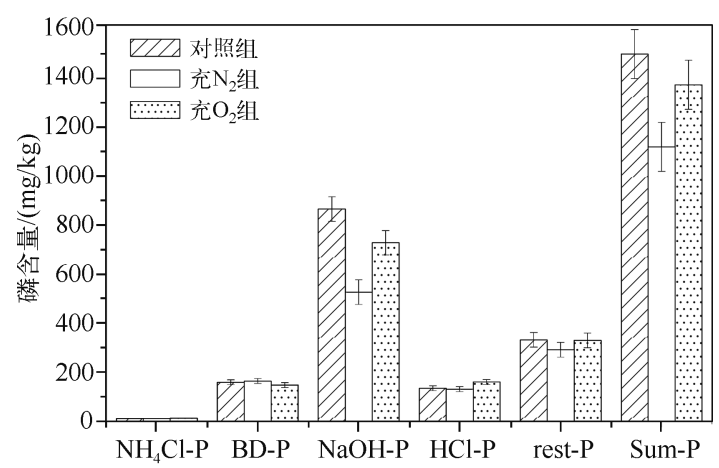

图 3 不同培养条件下沉积物中各形态磷含量

Fig.3 Each form of phosphorus in the sediment under different cultivate conditions

\section{3 不同培养条件下沉积物 $\mathrm{O}_{2} 、 \mathrm{H}_{2} \mathrm{~S}$ 浓度以及 $\mathrm{pH}$ 值的剖面变化}

不同培养条件下 $\mathrm{O}_{2}$ 的渗透深度与浓度均为: 充 $\mathrm{O}_{2}$ 组 $>$ 对照组>充 $\mathrm{N}_{2}$ 组. 自然条件下, 沉积物 $\mathrm{O}_{2}$ 的渗透深 度约为 $2.1 \mathrm{~mm}$ 左右, 界面 $\mathrm{O}_{2}$ 浓度为 $137 \mu \mathrm{mol} / \mathrm{L}$. 充 $\mathrm{N}_{2}$ 培养条件下, 界面 $\mathrm{O}_{2}$ 浓度为 $70 \mu \mathrm{mol} / \mathrm{L}, \mathrm{O}_{2}$ 的渗透深度 降低至 $0.9 \mathrm{~mm}$ 左右. 而充 $\mathrm{O}_{2}$ 培养之后, $\mathrm{O}_{2}$ 的渗透深度变为 $4.2 \mathrm{~mm}$, 约为自然状态的 2 倍 (图 4a).

自然、充 $\mathrm{O}_{2}$ 以及充 $\mathrm{N}_{2}$ 条件下, 沉积物内部产生的 $\mathrm{H}_{2} \mathrm{~S}$ 浓度存在较大差别. 自然条件下, $\mathrm{H}_{2} \mathrm{~S}$ 在沉积物约 $3 \mathrm{~mm}$ 处出现, 随后浓度开始增加, 到 $20.7 \mathrm{~mm}$ 处达到峰值 $(22.9 \mu \mathrm{mol} / \mathrm{L})$. 充 $\mathrm{O}_{2}$ 条件下, $\mathrm{H}_{2} \mathrm{~S}$ 的出现深度为 $15.9 \mathrm{~mm}$, 在 $33.9 \mathrm{~mm}$ 处达到峰值 $(9.0 \mu \mathrm{mol} / \mathrm{L})$. 充 $\mathrm{N}_{2}$ 培养的沉积物中, $\mathrm{H}_{2} \mathrm{~S}$ 的变化范围最大: 从沉积物表面 便开始产生 $\mathrm{H}_{2} \mathrm{~S}$, 并且随着深度增加 $\mathrm{H}_{2} \mathrm{~S}$ 快速增加, 在 $6 \mathrm{~mm}$ 深度处 $\mathrm{H}_{2} \mathrm{~S}$ 浓度达到峰值 $(47.3 \mu \mathrm{mol} / \mathrm{L})$, 随后 伴随深度的增加出现少许波动, 至 $12 \mathrm{~mm}$ 处开始下降 (图 4b).

不同氧化还原条件下沉积物 $\mathrm{pH}$ 值也存在明显差异. 3 种条件下沉积物 $\mathrm{pH}$ 值在 $4.2 \mathrm{~mm}$ 处发生交叉. $4.2 \mathrm{~mm}$ 处的 $\mathrm{pH}$ 值为 $6.9 ; 4.2 \mathrm{~mm}$ 以上沉积物 $\mathrm{pH}$ 值均大于 6.9 , 且大小顺序为: 充 $\mathrm{O}_{2}$ 组 $>$ 对照组 $>$ 充 $\mathrm{N}_{2}$ 组; 而 $4.2 \mathrm{~mm}$ 以下 $\mathrm{pH}$ 值均小于 6.9 , 且顺序为: 充 $\mathrm{N}_{2}$ 组 $>$ 对照组 $>$ 充 $\mathrm{O}_{2}$ 组 (图 $4 \mathrm{c}$ ). 

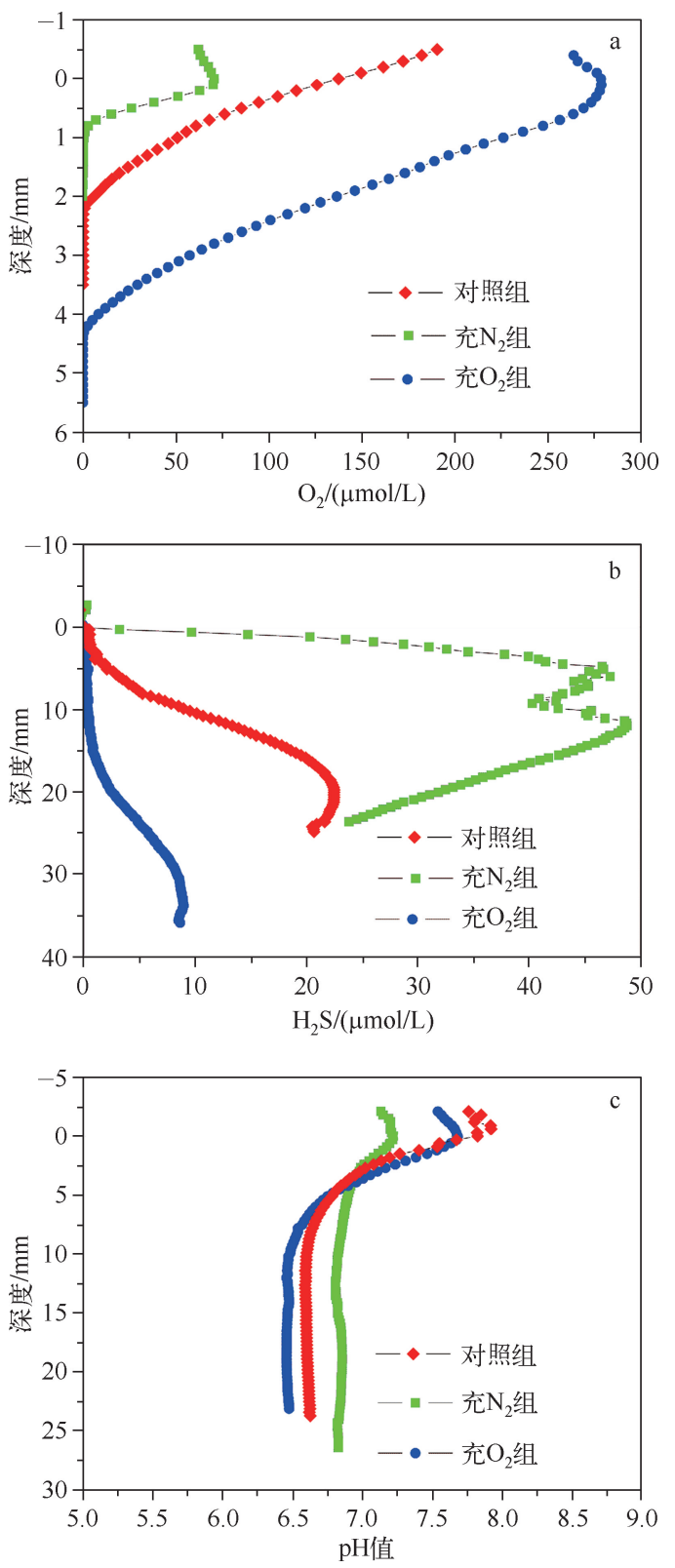

图 4 不同培养条件下沉积物 $\mathrm{O}_{2}$ 浓度、 $\mathrm{H}_{2} \mathrm{~S}$ 浓度和 $\mathrm{pH}$ 值的剖面分布

Fig.4 The profile distribution of $\mathrm{O}_{2}$ concentration, $\mathrm{H}_{2} \mathrm{~S}$ concentration and $\mathrm{pH}$ value of sediment under different cultivate conditions

\section{3 讨论}

\section{1 溶解氧对沉积物 $\mathrm{NaOH}-\mathrm{P}$ 释放的影响}

已有研究表明, 溶解氧主要通过影响 NaOH-P 而影响沉积物内源磷的释放 ${ }^{[6]}$. NaOH-P 是受铁铝 金属氧化物约束的磷, 该形态磷的沉淀与溶解是决 定沉积物内源磷释放与否的关键 ${ }^{[23]}$. 韩伟明 ${ }^{[24]}$ 在 西湖沉积物磷释放实验中发现 $\mathrm{NaOH}-\mathrm{P}$ 是沉积物释 放的主要磷赋存形态. 红枫湖沉积物中 $\mathrm{NaOH}-\mathrm{P}$ 在 总磷中所占比例最高, 平均为 $57.8 \%$. 对沉积物孔隙 水中 SRP 浓度、沉积物磷形态以及沉积物内部 $\mathrm{O}_{2}$ 和 $\mathrm{H}_{2} \mathrm{~S}$ 剖面分布特征的对比分析表明: 经过充 $\mathrm{N}_{2}$ 培 养的沉积物与自然状态下的沉积物相比, 沉积物内 部 $\mathrm{O}_{2}$ 浓度和渗透深度都有了大幅降低, 与此同时, 孔隙水中 SRP 浓度明显升高, 而沉积物磷形态中 $\mathrm{NaOH}-\mathrm{P}$ 和总磷含量明显降低, 其他沉积物磷形态 未发生显著变化. 这反映在沉积物内部 $\mathrm{O}_{2}$ 浓度降低 的情况下, 沉积物中的总磷含量降低的原因主要是 $\mathrm{NaOH}-\mathrm{P}$ 的释放, 并因此导致孔隙水中 SRP 浓度升 高. 此外, $\mathrm{O}_{2}$ 浓度的降低使得沉积物内部 $\mathrm{H}_{2} \mathrm{~S}$ 浓度 的剖面特征发生显著变化, 从界面开始, 硫酸根还 原产生大量的 $\mathrm{H}_{2} \mathrm{~S}, \mathrm{H}_{2} \mathrm{~S}$ 与二价铁离子产生硫化亚 铁沉淀 ${ }^{[25]}$, 铁离子的减少使得束缚 $\mathrm{NaOH}-\mathrm{P}$ 的能力 降低, NaOH-P 更易被释放到孔隙水中.

充 $\mathrm{O}_{2}$ 条件下沉积物 $\mathrm{NaOH}-\mathrm{P}$ 含量略有降低, 这 可能是曝气过程对沉积物造成了一定扰动, 导致沉 积物磷的少量释放 ${ }^{[26]}$.

\section{2 溶解氧对沉积物 rest-P 释放的影响}

从图 3 可知,沉积物总磷含量的降低除了主要 受到 $\mathrm{NaOH}-\mathrm{P}$ 含量降低影响之外, rest-P 的降低也 是部分原因. 沉积物 rest-P 主要为有机磷 ${ }^{[20]}$. 随着深 度的增加, $\mathrm{O}_{2}$ 浓度逐渐降低, 直至为 0 , 深度继续增 加, $\mathrm{H}_{2} \mathrm{~S}$ 开始出现 (图 4). 当微生物的耗氧超过了 $\mathrm{O}_{2}$ 在沉积物中的扩散速率时, 微生物便开始利用其它 氧化剂进行无氧呼吸, 电子受体优先顺序依次为溶 解氧、硝酸根离子、高价态铁锰、硫酸根离子 ${ }^{[27]}$. 当 电极监测到有 $\mathrm{H}_{2} \mathrm{~S}$ 产生时, 说明溶解氧、硝酸根离 子以及高价态铁锰等已经被还原. 在充 $\mathrm{O}_{2}$ 条件下, 好氧微生物占主导, 微生物消耗大量的 $\mathrm{O}_{2}$, 同时 $\mathrm{pH}$ 值升高, 而 rest-P 含量几乎没有变化, 说明好氧微生

物并不消耗有机磷. 而在充 $\mathrm{N}_{2}$ 条件下, 厌氧微生物占主导, 消耗硫酸根, 产生了大量的 $\mathrm{H}_{2} \mathrm{~S}$, 使 $\mathrm{pH}$ 值降低, 同 时, rest-P 含量降低, 可能是戻氧微生物消耗了有机质, 将有机磷转变为无机磷, 进而释放到上覆水体 ${ }^{[4]} . \mathrm{O}_{2}$ 浓度决定好氧微生物与厌氧微生物的比例, 因而影响有机磷的迁移转化. 


\section{3 不同条件下沉积物 $\mathrm{O}_{2}$ 的扩散通量}

沉积物与上覆水之间的相互作用已经引起广泛关注 ${ }^{[28-29]}$, 了解不同条件下氧气的分布, 可以估算出氧 气的扩散通量,进而可以对扩散边界层中的微生物分布和营养物质的迁移转化进行定量研究. 自然状态下红 枫湖沉积物 $\mathrm{O}_{2}$ 的扩散通量为 $235.6 \mathrm{nmol} /\left(\mathrm{m}^{2} \cdot \mathrm{s}\right)\left(20.4 \mathrm{mmol} /\left(\mathrm{m}^{2} \cdot \mathrm{d}\right)\right)$, 这与汪嘉宁等在青岛会场湾所测 得的 $\mathrm{O}_{2}$ 的扩散通量 $\left(15.4 \sim 53.6 \mathrm{mmol} /\left(\mathrm{m}^{2} \cdot \mathrm{d}\right)\right)$ 接近 ${ }^{[30]}$, 而充 $\mathrm{N}_{2}$ 状态下, 沉积物 $\mathrm{O}_{2}$ 扩散通量仅为 $29.4 \mathrm{nmol} /$ $\left(\mathrm{m}^{2} \cdot \mathrm{s}\right)\left(2.5 \mathrm{mmol} /\left(\mathrm{m}^{2} \cdot \mathrm{d}\right)\right)$, 略低于王敬富等在红枫湖大坝自然缺氧状态下测出来的 $\mathrm{O}_{2}$ 扩散通量 $(7.65$ $\left.\mathrm{mmol} /\left(\mathrm{m}^{2} \cdot \mathrm{d}\right)\right)^{[31]}$, 这可能是由于人工制造的戻氧程度本身就要高于自然界的戻氧程度. 自然状态下沉积 物 $\mathrm{O}_{2}$ 的扩散通量为充 $\mathrm{N}_{2}$ 条件下的近 8 倍, 而充 $\mathrm{O}_{2}$ 条件下沉积物 $\mathrm{O}_{2}$ 扩散通量远远高于充 $\mathrm{N}_{2}$ 条件. 在沉积物 水界面处, 充 $\mathrm{O}_{2}$ 条件下微生物的耗氧活动和有机物的降解要比充 $\mathrm{N}_{2}$ 条件下更加剧烈, 但好氧环境下微生物 活动对磷的吸收使得有机磷并未明显释放, 而厌氧环境下微生物活动则显著促进了磷的释放 ${ }^{[32]}$. 这表明好 氧微生物和厌氧微生物对沉积物有机磷的影响存在重要差别.

红枫湖溶解氧的渗透深度为充 $\mathrm{O}_{2}$ 组 $>$ 对照组>充 $\mathrm{N}_{2}$ 组. 龚春生等 ${ }^{[33]}$ 对不同溶解氧水平下的底泥研究发现, 沉积物间隙水中的好氧层会随上覆水溶解氧浓度的增大而增厚, 好氧层的增厚会加大沉积物与上覆水之间的 物质传输阻力. 充 $\mathrm{O}_{2}$ 状态与充 $\mathrm{N}_{2}$ 状态相比, 其沉积物具有更厚的好氧层, 因而抑制了内源磷的释放. Vopel 等 ${ }^{[34]}$ 发现即使没有光或者光很弱, 沉积物表面的微生物垫也能产生氧气, 因此在自然、充 $\mathrm{O}_{2}$ 或者充 $\mathrm{N}_{2}$ 状态下, 氧气剖面均出现典型的界面放氧现象. 虽然整个实验过程是在避光环境下开展的,但由于实验过程需要每天充 气, 因此实验室并不能保持始终黑暗, 微生物垫表层应该也产生了一定量的 $\mathrm{O}_{2}$. 在自然、充 $\mathrm{O}_{2}$ 或者充 $\mathrm{N}_{2}$ 状态 下, 沉积物一水界面都存在上覆水复氧与微生物垫产氧, 但三者溶解氧的走势存在明显差异: 在自然状态下均 匀下降, 而充 $\mathrm{O}_{2}$ 和充 $\mathrm{N}_{2}$ 状态下, 溶解氧在刚接触沉积物一水界面时呈升高的趋势, 而后才逐渐降低.

\section{4 结论}

1) 厌氧条件下红枫湖沉积物 TP 含量显著降低, 且主要是 $\mathrm{NaOH}-\mathrm{P}$ 和 rest-P 含量降低所致, 厌氧条件下 沉积物孔隙水中磷酸盐浓度明显升高, 而好氧条件下沉积物孔隙水磷酸盐浓度显著降低, 表明厌氧条件显 著促进了红枫湖沉积物磷释放.

2) 厌氧条件下沉积物含氧量下降、硫还原活动强烈是导致 NaOH-P 释放的主要原因. 微电极分析结果 表明, 与对照组相比, 厌氧条件下界面 $\mathrm{O}_{2}$ 浓度降低至 $70 \mu \mathrm{mol} / \mathrm{L}$ ( 对照组为 $137 \mu \mathrm{mol} / \mathrm{L}$ ), 氧渗透深度降低为 $0.9 \mathrm{~mm}$ (对照组为 $2.1 \mathrm{~mm}$ ) , $\mathrm{H}_{2} \mathrm{~S}$ 浓度升高至 $47.3 \mu \mathrm{mol} / \mathrm{L}$ (对照组为 $22.9 \mu \mathrm{mol} / \mathrm{L}$ ).$_{2}$ 浓度的降低加速了沉 积物磷酸盐的还原作用并产生大量 $\mathrm{H}_{2} \mathrm{~S}$, 进而与二价铁离子形成硫化亚铁沉淀, 最终导致 NaOH-P ( Fe-P) 释 放到孔隙水中.

3) 好氧向戻氧条件的转换可通过改变沉积物内部 $\mathrm{pH}$ 值分布和微生物活动, 促使 rest-P (有机磷) 减少. 微电极分析结果表明, 好氧条件下, rest-P 含量几乎没有变化, 而厌氧条件下, 厌氧微生物不仅可以消耗硫酸 根产生 $\mathrm{H}_{2} \mathrm{~S}$, 导致 $\mathrm{pH}$ 值降低, 还可消耗有机质, 将有机磷转变为无机磷. $\mathrm{O}_{2}$ 浓度决定了好氧微生物与厌氧微 生物的比例,因而影响了有机磷的迁移转化.

4) 沉积物一水界面氧化还原环境可影响沉积物氧渗透深度、 $\mathrm{pH}$ 值分布、微生物活动、硫循环以及有机 质降解过程,进而控制沉积物磷的形态转化与释放.

5) 联合应用微电极技术和沉积物磷形态分析对湖泊沉积物一水界面开展微尺度观测研究是揭示沉积 物内源磷释放机制与控制因素的有效途径, 但前者分辨率为 $\mathrm{mm}-\mu \mathrm{m}$ 级尺度, 而后者分辨率为 $\mathrm{cm}$ 级尺度, 如 何进行更有效的衔接和对比研究值得今后继续探索.

\section{5 参考文献}

[ 1 ] 秦伯强, 高 光, 朱广伟等. 湖泊富营养化及其生态系统响应. 科学通报, 2013, 58: 855-864.

[ 2 ] Rydin E. Potentially mobile phosphorus in Lake Erken sediment. Water Research, 2000, 34: 2037-2042.

[ 3 ] 金相灿, 王圣瑞, 庞 燕. 太湖沉积物磷形态及 $\mathrm{pH}$ 值对磷释放的影响. 中国环境科学, 2004, 24(6) : 707-711.

[ 4 ] 侯立军, 刘 敏, 许世远. 环境因素对苏州河市区段底泥内源磷释放的影响. 上海环境科学, 2003, 22(4): 
258-260.

[ 5 ] Røy H, Huettel M, Jørgensen BB. Transmission of oxygen concentration fluctuation through the diffusive boundary layer overlying aquatic sediments. Limnology and Oceanography, 2004, 49(3) : 686-692.

[6] 步青云. 浅水湖泊溶解氧变化对沉积物磷、氮的影响 [学位论文]. 北京: 中国环境科学研究院, 2006.

[ 7 ] Kisand A, Noges P. Sediment phosphorus release in phytoplankton dominated versus macrophyte dominated shallow lakes: Importance of oxygen conditions. Hydrobiologia, 2003, 506/507/508/509(1/2/3) : 129-133.

[ 8 ] Hupfer M, Lewandowski J. Oxygen controls the phosphorus release from lake sediments—a long lasting paradigm in limnology. International Review of Hydrobiology, 2008, 93(4/5) : 415-432.

[ 9 ] 韩沙沙, 温琰茂. 富营养化水体沉积物中磷的释放及其影响因素. 生态学杂志, 2004, 23(2): 98-101.

[10] 林 艳, 刘亚丽, 段秀举. 双龙湖底泥磷释放强度影响因素正交试验研究. 资源环境与工程, 2006, 20(1): 78-88.

[11] Span D, Arbouille D, Howa H et al. Variation of nutrient stocks in the superficial sediments of the Lake Geneva from 1978 to 1988. Hydrobiologia, 1990, 207: 161-166.

[12] Baudo R, Giesy JP, Muntau H. Sediments: Chemistry and toxicity of in-place pollutants. Michigna: Lewis Publishers, 1990: 131-144.

[13] 刘素美, 张 经. 沉积物间隙水的几种制备方法. 海洋环境科学, 1999, 18(2): 66-71.

[14] 许昆明, 胡融刚. 微电极技术在沉积物化学原位测量中的应用. 地球科学进展, 2006, 21(8): 863-869.

[15] Beyenal H, Babauta J. Microsensors and microscale gradients in biofilms. Advances in Biochemical Engineering/Biotechnology, 2013, 146: 235-256.

[16] 王建军, 沈 洁, 张 路等. 湖泊沉积物一水界面氧气交换速率的测定及影响因素. 湖泊科学, 2009, 21(4): 474482. DOI 10. 18307/2009. 0404.

[17] 王敬富, 陈敬安, 曾 艳等. 贵州红枫湖沉积物磷赋存形态的空间变化特征. 湖泊科学, 2012, 24(5): 789-796. DOI 10. 18307/2012. 0521.

[18] Chen JA, Zhang W, Zhang RY et al. Time and spatial distribution characteristics of nitrogen and phosphorus in the sediment of Lake Hongfeng. 13th World Lake Conference, 2009: 2226-2230.

[19] 李 键, 张 维, 陈敬安等. 一种可实现不同水深条件下采样的湖泊沉积物柱芯采样装置. 地球与环境, 2011,39 (1) : 121-124.

[20] Hupffer M, Gfichter R, Giovano R et al. Transformation of phosphorus species in settling seston and during early sediement diagenesis. Aquatic Sciences, 1995, 57(4) : 305-324.

[21] Crank J. The mathematics of diffusion. Landon: Oxford University Press, 1975.

[22] Sandler SI. The 100 most cited articles in AIChE Journal history. AIChE Journal, 2004, 50(1) : 4-6.

[23] Ruban V, López-Sánchez JF, Pardo P et al. Selection and evaluation of sequential extraction procedures for the determination of phosphorus forms in lake sediment. Journal of Environmental Monitoring, 1999, 1: 51-56.

[24] 韩伟明. 底泥释磷及其对杭州西湖富营养化的影响. 湖泊科学, 1993, 5(1) : 71-77. DOI 10. 18307/1993. 0110.

[25] 万国江, 陈振楼, 万 犧等. 湖泊沉积物一水界面铁一锰循环研究新进展. 地质地球化学, 1996, (2): 5-8.

[26] 孙慧卿, 王 平, 江和龙. 不同模拟条件下太湖沉积物一水界面磷行为的研究. 环境科学与技术, 2012, 35( 5) : 141-146.

[27] 许昆明, 司靖宇. 适用于海洋沉积物间隙水中氧、锰 II 、铁 II 、硫分析的金录齐微电极. 分析化学研究报告, 2007, 35(8) : 1147-1150.

[28］吴丰昌, 万国江, 蔡玉蓉. 沉积物一水界面的生物地球化学作用. 地球科学进展, 1996, 11(2): 191-1971.

[29] Dade WB, Hogg AJ, Boudreau BP. Physics of flow above the sediment-water interface. In: Boudreau BP, Jorgensen BB eds. The benthic boundary layer: Transport processes and biogeochemistry. Oxford: Oxford University Press, 2001: 4-43.

[30] 汪嘉宁, 赵 亮, 魏 皓. 潮滩动力过程影响下扩散边界层和沉积物一水界面扩散通量的变化. 科学通报, 2012, 57(8): 656-665.

[31] 王敬富, 陈敬安, 曾 艳等. 微电极测量系统在湖泊沉积物一水界面生物地球化学过程研究中的应用. 地球与环 境, 2013, 41(1): 65-70.

[32] 孙晓杭, 张 昱, 张斌亮等. 微生物作用对太湖沉积物磷释放影响的模拟实验研究. 环境化学, 2006, 25(1): 24-27.

[33] 龚春生, 范成新. 不同溶解氧水平下湖泊底泥一水界面磷交换影响因素分析. 湖泊科学, 2010, 22(3): 430-436. DOI 10. 18307/2010. 0317.

[34] Vopel K, Hawes I. Photosynthetic performance of benthic microbial mats in Lake Hoare, Antarctica. Limnology and Oceanography, 2006, 51(4): 1801-1812. 